\title{
Combined effect of Sn addition and pre-ageing on natural secondary and artificial ageing of $\mathrm{Al}-\mathrm{Mg}-\mathrm{Si}$ alloys
}

\author{
Xingpu Zhang ${ }^{1,2,3, *}$ (D), Meng $\mathrm{Liu}^{1,2, *}$, Jiangwei Wang ${ }^{3}$, Jixue $\mathrm{Li}^{3}$, and John Banhart ${ }^{1,2}$ \\ ${ }^{1}$ Technische Universität Berlin, Hardenbergstraße 36, 10623 Berlin, Germany \\ ${ }^{2}$ Helmholtz-Zentrum Berlin Für Materialien und Energie, Hahn-Meitner-Platz 1, 14109 Berlin, Germany \\ ${ }^{3}$ Center of Electron Microscopy and State Key Laboratory of Silicon Materials, School of Materials Science and Engineering, \\ Zhejiang University, Hangzhou 310027, People's Republic of China
}

Received: 7 August 2021

Accepted: 22 October 2021

Published online:

3 January 2022

(C) The Author(s) 2021

\begin{abstract}
Both $\mathrm{Sn}$ addition and pre-ageing are known to be effective in maintaining the artificial ageing potential after natural ageing of $\mathrm{Al}-\mathrm{Mg}-\mathrm{Si}$ alloys. In this study, the combined effects of $\mathrm{Sn}$ addition and pre-ageing at $100{ }^{\circ} \mathrm{C}$ or $180{ }^{\circ} \mathrm{C}$ on natural secondary ageing and subsequent artificial ageing of an alloy AA6014 were investigated using hardness, electrical resistivity, differential scanning calorimetry and transmission electron microscopy characterizations. It is found that pre-ageing can suppress natural secondary ageing and improve the artificial ageing hardening kinetics and response after 1 week of natural secondary ageing in both alloys with and without Sn addition. The effect of pre-ageing at $100{ }^{\circ} \mathrm{C}$ is more pronounced in the Sn-free alloy while the combination of preageing at $180{ }^{\circ} \mathrm{C}$ and adding Sn shows superiority in suppressing natural secondary ageing and thus avoiding the undesired hardening before artificial ageing. Moreover, when natural ageing steps up to $8 \mathrm{~h}$ are applied before preageing at $100{ }^{\circ} \mathrm{C}$, the effect of pre-ageing in Sn-added alloy can be further improved. The influence of $\mathrm{Sn}$ on vacancies at different ageing temperatures is discussed to explain the observed phenomena.
\end{abstract}

Handling Editor: Catalin Croitoru.

Address correspondence to E-mail: xingpu.zhang@zju.edu.cn; meng.liu@helmholtz-berlin.de 


\section{GRAPHICAL ABSTRACT}
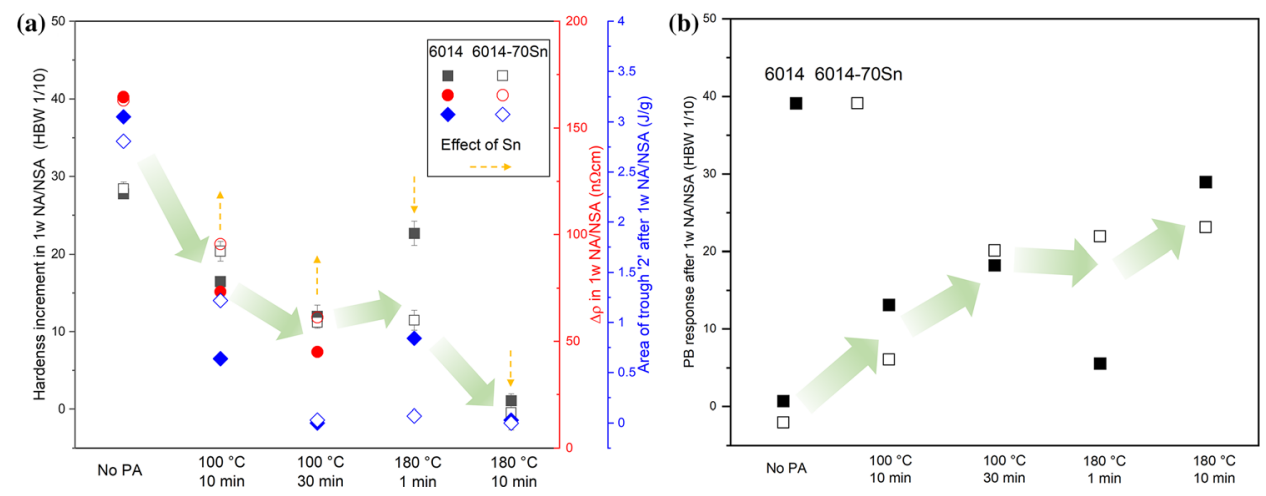

\section{Introduction}

The age-hardenability of Al-Mg-Si alloys is of great importance for their industrial application. Ideally, artificial ageing (AA) at $\sim 180^{\circ} \mathrm{C}$ is carried out immediately after quenching from the solutionising temperature $\left(\sim 540^{\circ} \mathrm{C}\right)$ to strengthen the alloys by the formation of needle-like monoclinic $\beta^{\prime \prime}$ precipitates $[1,2]$. In practice, however, a delay at room temperature (RT) after solutionising is inevitable and leads to a reduction in the hardening kinetics and the achievable strength during the following AA [3-5]. One reason for this negative effect of natural ageing (NA) lies in the fact that clusters formed during NA cannot transform into $\beta^{\prime \prime}$ during AA [6] but rather reduce the solute supersaturation. Another possible explanation might be that the vacancy concentration, which plays a vital role in the diffusion of solute atoms, is lowered by the annihilation of vacancies by sinks [7] and the "vacancy-prison" effect of the formed NA clusters [8]. To compensate the adverse effect of NA, various methods have been developed over the past decades.

One viable method is microalloying the $\mathrm{Al}$ alloy with $\mathrm{Sn}$, which can bind with vacancies strongly at RT. As the diffusion of solute atoms requires vacancies, a reduction of available vacancies can greatly retard the undesired NA [9]. Upon subsequent AA, the binding between $\mathrm{Sn}$ atoms and vacancies weakens and some of the trapped vacancies are released, thus facilitating the subsequent precipitation and establishment of the vacancy equilibrium at $180{ }^{\circ} \mathrm{C}$ [9]. As a result, a significant AA hardening potential can be obtained in a Sn-added alloy even after long NA [10].

Another commonly used method is pre-ageing (PA). In this approach, samples are artificially underaged immediately after solutionising and quenching, which improves the AA response after NA [4, 11-16]. The PA temperature is normally above a critical value $\left(\sim 67^{\circ} \mathrm{C}\right)$ and favours the formation of PA clusters, which then may further grow into $\beta^{\prime \prime}$ precipitates during the following AA [17]. Note that in this paper, the term "PA cluster" is used to label the phase formed during PA, regardless of the different notations found in the literature, including PA cluster [15], Cluster (2) [18], GP zone [19, 20] and pre$\beta^{\prime \prime}$ [21]. Although pre-ageing has been proved to be efficient in diminishing the negative effect of NA, the accompanying strength increase and also the strengthening during following natural secondary ageing (NSA) reduces formability. Therefore, it has been suggested by some researchers $[14,22]$ that the PA time and temperature must be controlled in order to achieve a trade-off between an acceptable formability and a good AA response. The above-mentioned potential of added Sn in maintaining the alloy's stability at RT might provide additional freedom in finding favourable conditions, which has been the motivation for this work.

Moreover, the effect of microalloying (e.g. $\mathrm{Cu}$ and $\mathrm{Ag}$ ) on the performance of PA has been investigated. It was found that $\mathrm{Cu}$ addition modifies the cluster 
composition and enhances the formation of clusters that can act as precursors of elongated precipitates [23]. Weng et al. [24] claimed that the attractive interaction between $\mathrm{Cu} / \mathrm{Ag}$ and $\mathrm{Mg}$ enables the nucleation of $\mathrm{Mg}-\mathrm{Si}-\mathrm{Cu}(\mathrm{Ag})$ co-clusters and therefore increases the number density of PA clusters. Nevertheless, the possibility of combining PA treatment and $\mathrm{Sn}$ addition in diminishing the detrimental effect of NA on the subsequent AA (both hardening rate and peak strength) has so far received little attention. A strategy in realizing the potential of these two methods concurrently is still pending. Thus, in the present work, we explore this possibility systematically. PA at both low and high temperatures $\left(100{ }^{\circ} \mathrm{C}\right.$ and $180{ }^{\circ} \mathrm{C}$ ) is carried out on $\mathrm{Al}-\mathrm{Mg}-\mathrm{Si}$ alloys with and without $\mathrm{Sn}$ addition, and the mechanism controlling the following natural secondary ageing (NSA) and artificial ageing (AA) is clarified. Moreover, a designed combination of PA and Sn addition should contribute to overcoming the negative effect of NA on AA.

\section{Experimental}

Industrial AA6014 alloys with and without Sn were manufactured by the Novelis Research and Technology Center Sierre and received as sheets of $1 \mathrm{~mm}$ thickness. The alloy compositions are given in Table 1 . The two alloys contain the same total amount (1.35 at.\%) of main alloying elements, but differ slightly in $\mathrm{Mg}, \mathrm{Si}$ and $\mathrm{Cu}$ contents. Solution heat treatment (SHT) was performed at $570{ }^{\circ} \mathrm{C}$ for $60 \mathrm{~min}$ with argon as a protective gas followed by a quench in ice water. Samples were then either stored in an incubator running at $20^{\circ} \mathrm{C}$ for NA or immersed into an oil bath held at $100{ }^{\circ} \mathrm{C}$ or liquid metal (LM) $\mathrm{Bi}_{57}$ $\mathrm{Sn}_{43}$ at $180{ }^{\circ} \mathrm{C}$ for PA. After PA, the same incubator was employed for the subsequent NSA. Optional natural ageing at $20^{\circ} \mathrm{C}$ for $4 \mathrm{~h}$ or $8 \mathrm{~h}$ was conducted before PA at $100{ }^{\circ} \mathrm{C}$ for alloy 6014-70Sn. Final AA was carried out in LM at $180{ }^{\circ} \mathrm{C}$ after 1 week of NA/NSA.
30 min AA is used to simulate a typical paint baking (PB). The heat treatment procedures are described in Fig. 1.

After heat treatments, Brinell hardness was measured by employing a Qness $60 \mathrm{M}$ tester $(1 \mathrm{~mm}$ diameter tungsten carbide indenter, $10 \mathrm{~kg}$ load and $10 \mathrm{~s}$ loading time). At least 10 indentations were performed for each sample. In-situ electrical resistivity measurements were performed using a fourpoint probe system with a current of $100 \mathrm{~mA}$. Sample wires (usually $500 \mathrm{~mm}$ long, $0.82 \mathrm{~mm}$ in diameter) were kept in an oil bath at $20^{\circ} \mathrm{C}$ during the measurements. The change of resistivity $(\Delta \rho)$ during NA/ NSA is calculated by subtracting the initial value measured after 2 min to 3 min NA/NSA. Differential scanning calorimetry (DSC) measurements were carried out on 1-mm thick samples of $5 \mathrm{~mm}$ diameter in a Netzsch 204 F1 Phoenix, with a reference sample of pure $\mathrm{Al}$ (99.999\%). To avoid storage at RT, samples were stored in liquid nitrogen immediately after the various heat treatments. After being held for $5 \mathrm{~min}$ in the pre-cooled $\left(0{ }^{\circ} \mathrm{C}\right)$ chamber, DSC analyses were performed from 0 to $400{ }^{\circ} \mathrm{C}$ with a scanning rate of $10 \mathrm{~K} \mathrm{~min}^{-1}$. The curve obtained with two empty crucibles was used as the baseline. For TEM characterizations, samples were firstly ground to less than $0.1 \mathrm{~mm}$ in thickness, punched into discs $(3 \mathrm{~mm}$ in diameter) and then electrolytically thinned with electrolyte of 24 vol.\% nitric acid and 76 vol.\% methanol at $-30{ }^{\circ} \mathrm{C}$. TEM images were obtained using a FEI Tecnai G2 F20 S-TWIN TEM operated at $200 \mathrm{kV}$. High-angle annular dark-field scanning transmission electron microscopy (HAADF-STEM) imagining was performed on a spherical aberration probe corrected FEI Titan G $^{2}$ 80-200 ChemiSTEM operated at $200 \mathrm{kV}$.

Table 1 Chemical compositions of the alloys as determined by inductively coupled plasma optical emission spectrometry (except for Sn). For $\mathrm{Sn}$, a nominal value is given

\begin{tabular}{lllllll}
\hline Alloy \& compsition & $\mathrm{Mg}($ at.\%) & Si (at.\%) & Sn (at. ppm) & Cu (at.\%) & Fe (at.\%) & Mn (at.\%) \\
\hline 6014 & 0.72 & 0.58 & - & 0.05 & 0.09 & 0.04 \\
$6014-70 \mathrm{Sn}$ & 0.81 & 0.54 & 70 & - & 0.12 & 0.04 \\
\hline
\end{tabular}



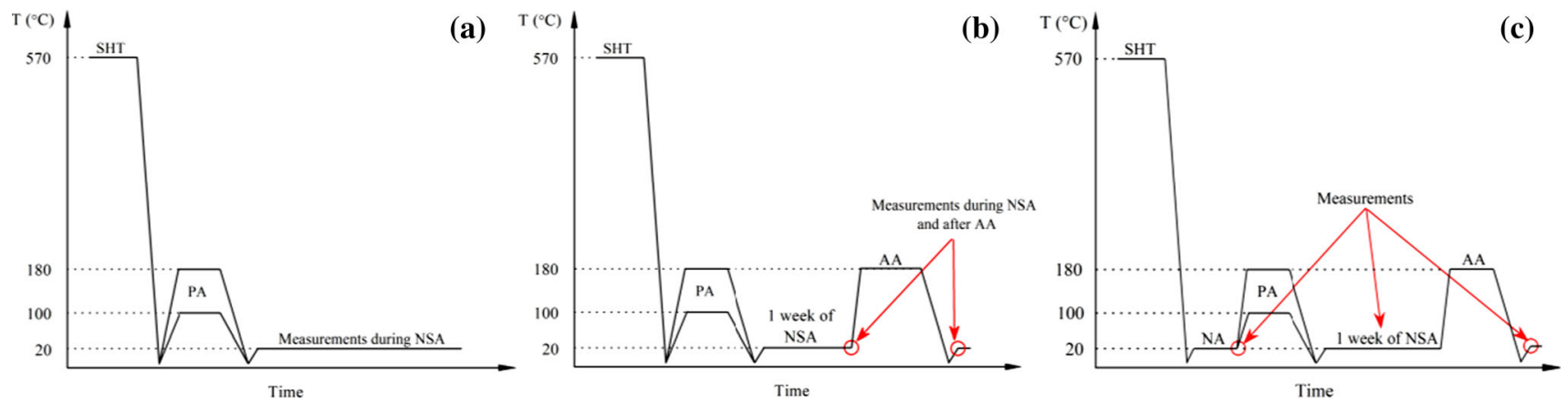

Figure 1 Schematic representation of heat treatment procedures. Measurements were carried out $\mathbf{a}$ during NSA, $\mathbf{b}$ after 1 week of NA/ NSA and subsequent AA, and $c$ to study the influence of NA before PA.

\section{Results}

\section{State during natural (secondary) ageing (NA/NSA)}

After solutionising and quenching, Sn addition delays hardening during NA. Alloy 6014 shows a continuous hardness increase upon ageing, while alloy 6014-70Sn maintains a nearly constant hardness for $8 \mathrm{~h}$ before an increase is observed (grey lines in Fig. 2). After $1 / 2$ year, both alloys reach $\sim 72 \mathrm{HBW}$. For the PA-treated alloys, the hardness shows substantial increase at both $100{ }^{\circ} \mathrm{C}$ and $180{ }^{\circ} \mathrm{C}$, though hardening of alloy 6014 is more pronounced than that of alloy 6014-70Sn, see the insets in Fig. 2. Such PA treatment can greatly retard the following hardening during NSA of both alloys. When the time of PA

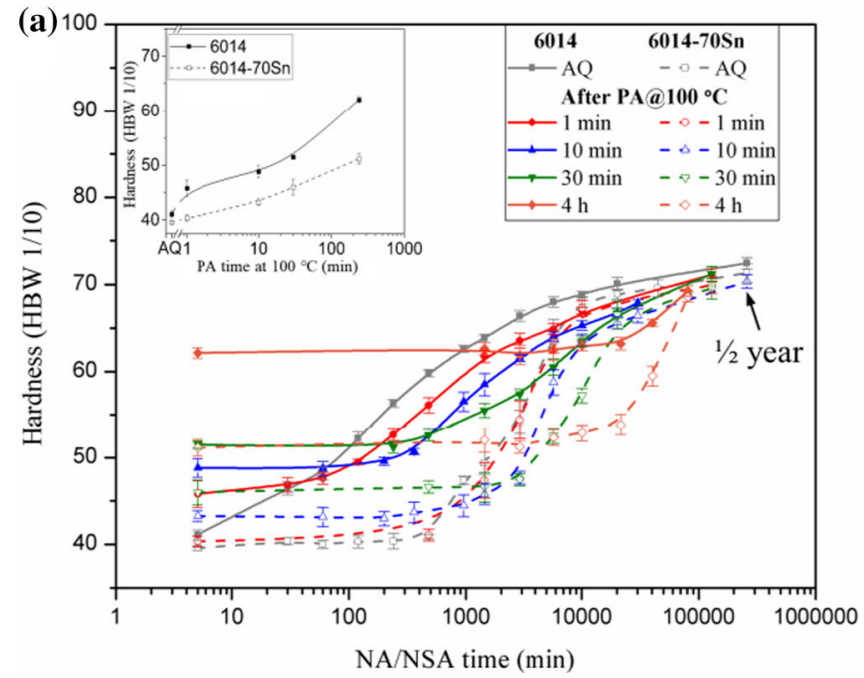

Figure 2 Hardness evolution during NA and NSA after PA at a $100{ }^{\circ} \mathrm{C}$ and $\mathbf{b} 180{ }^{\circ} \mathrm{C}$ for alloys $6014(\mathrm{Sn})$. “AQ” refers to the asquenched state directly after solutionizing and quenching. The treatment is $\geq 10 \mathrm{~min}$ at $100{ }^{\circ} \mathrm{C}$ and $\geq 1 \mathrm{~min}$ at $180{ }^{\circ} \mathrm{C}$, respectively, a stage of initially constant hardness appears in alloy 6014.

Figure 3 shows the change of electrical resistivity of 6014(Sn) alloys during NA and NSA. During NA, the resistivity increase of alloy 6014 exhibits distinct stages on the logarithmic time scale, similar to the observations in our previous study [25]. Sn addition markedly slows down the resistivity change and only after $\sim 1$ week of NA the resistivity increases of these two alloys reach a comparable value. For both alloys, PA not only slows down the resistivity increase but also reduces the value achieved within 1 week of NSA. The initiation of resistivity increase in alloy 6014-70Sn occurs later than the alloy 6014 after the same PA treatment at $100{ }^{\circ} \mathrm{C}$, but eventually reaches higher values than the $\mathrm{Sn}$-free alloy.

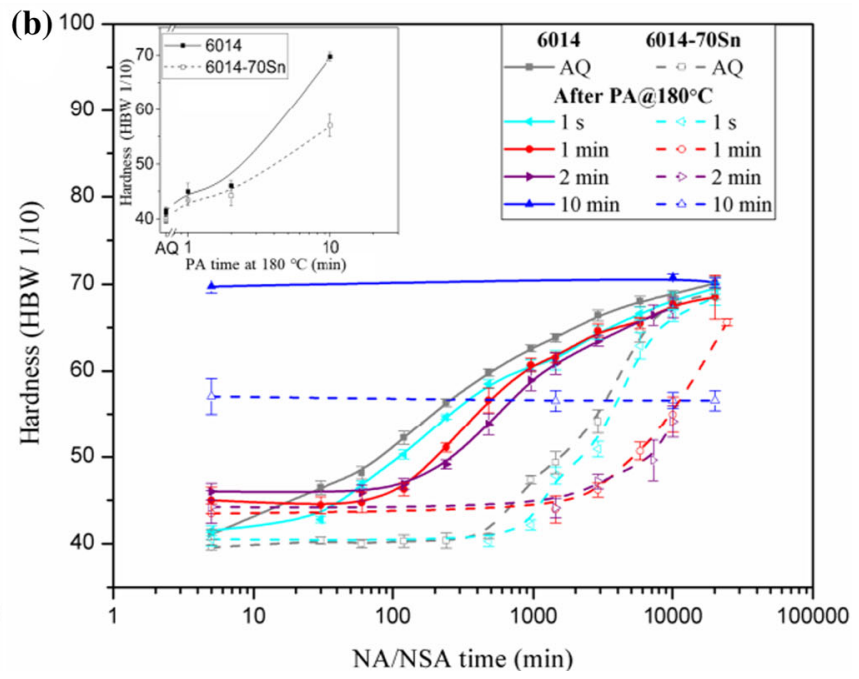

hardness evolution during PA at $\mathbf{a} 100{ }^{\circ} \mathrm{C}$ and $\mathbf{b} 180{ }^{\circ} \mathrm{C}$ is given in the insets (more data for longer PA times can be found in [26]). 


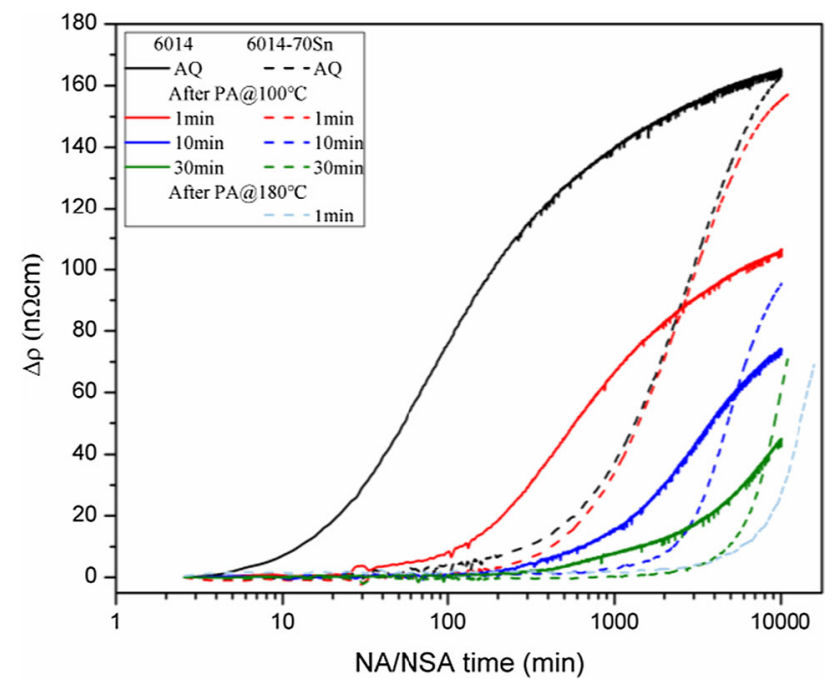

Figure 3 Changes of electrical resistivity in alloys 6014(Sn) during NA and NSA.

\section{State after 1 week of natural (secondary) (NA/NSA) and subsequent artificial ageing (AA)}

DSC analysis of 6014(Sn) alloys after various heat treatments is shown in Fig. 4. Right after quenching ("AQ", grey lines), alloy 6014 exhibits three exothermic peaks caused by the formation of clusters (around $75^{\circ} \mathrm{C}$ ), $\beta^{\prime \prime}$ precipitates (around $247^{\circ} \mathrm{C}$ ) and $\beta^{\prime}$ (around $298^{\circ} \mathrm{C}$ ). The corresponding DSC curve of the as-quenched alloy 6014-70Sn shows a comparable shape but with evident discrepancy: the cluster peak is much smaller and the $\beta^{\prime \prime}$ and $\beta^{\prime}$ peaks appear at higher temperatures. The cluster peak of alloy 6014 is reduced strongly by 1 week of NA but besides this NA shows a similar influence on the DSC trace of both alloys: An endothermic cluster dissolution trough [19] appears right before the $\beta^{\prime \prime}$ peak and both $\beta^{\prime \prime}$ and $\beta^{\prime}$ peaks are delayed to higher temperatures. When PA is applied to the two alloys, the dissolution trough is gradually diminished and the $\beta^{\prime \prime}$ and $\beta^{\prime}$ peaks are shifted to lower temperatures as PA times increase.

Figure 5 compares the hardness before and after 1 week of NA/NSA in these two alloys as well as its evolution during subsequent AA. The hardness right after quenching with and without ensuing PA is taken from Fig. 2 and marked with green boxes. After quenching and 1 week of NA, a hardness value $69 \mathrm{HBW}$ is reached for both alloys. When PA is carried out, the hardness after 1 week of NSA is smaller and the reduction is much more pronounced in alloy 6014-70Sn than in alloy 6014 (orange boxes). During subsequent AA, hardnesses of as-quenched 6014(Sn) alloys increase continuously (grey curves), from the initial $\sim 40 \mathrm{HBW}$ to a saturation value of $\sim 109 \mathrm{HBW}$ for both alloys. After 1 week of prior NA, a hardening stagnation or even a slight hardness drop is observed in the early stage of AA in both alloys (black curves). NA also delays the AA kinetics and reduces the AA hardening response. Compared to the alloys only naturally aged for 1 week, alloys after PA and NSA do not show any initial decrease during AA except for alloy 6014 after 1 min PA at $180{ }^{\circ} \mathrm{C}$. The prior PA also accelerates the hardness increase and improves the achievable hardness.
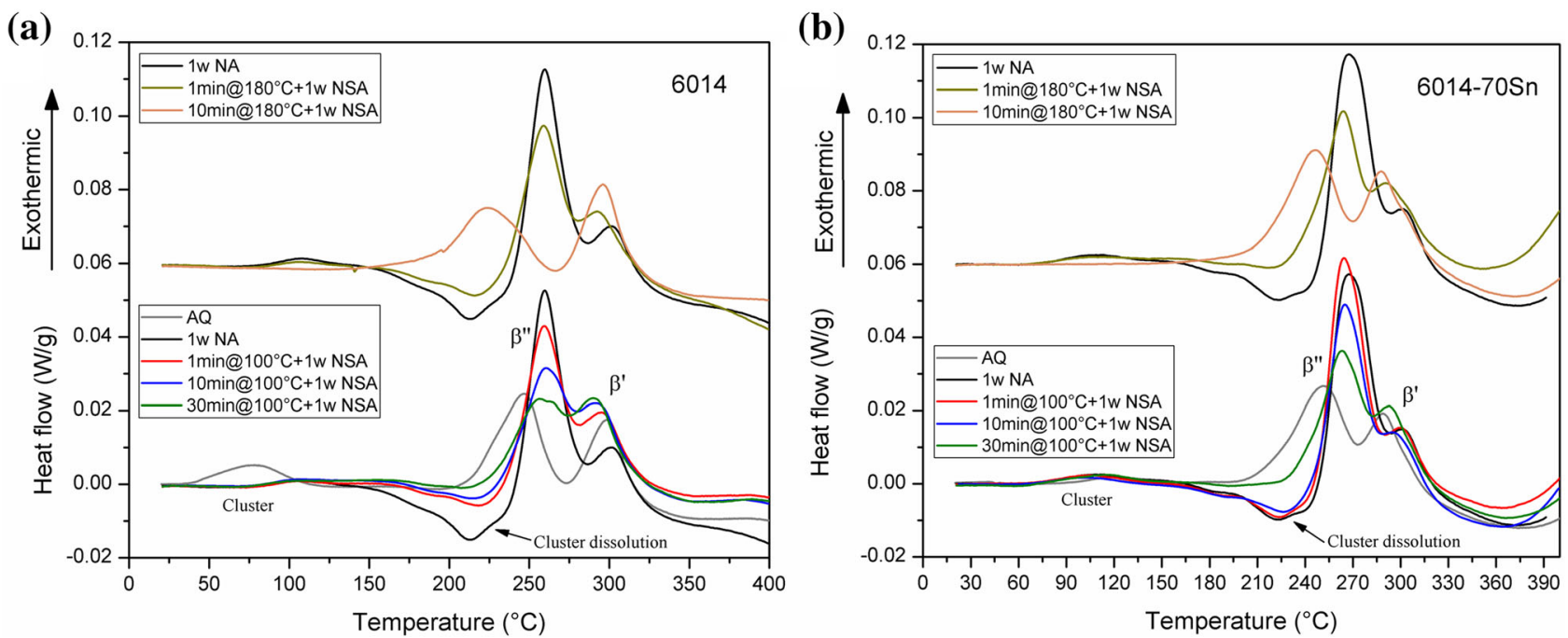

Figure 4 DSC traces in alloys a 6014 and b $6014-70 \mathrm{Sn}$ after various heat treatments measured at a scanning rate of $10 \mathrm{~K} \cdot \mathrm{min}^{-1}$. 

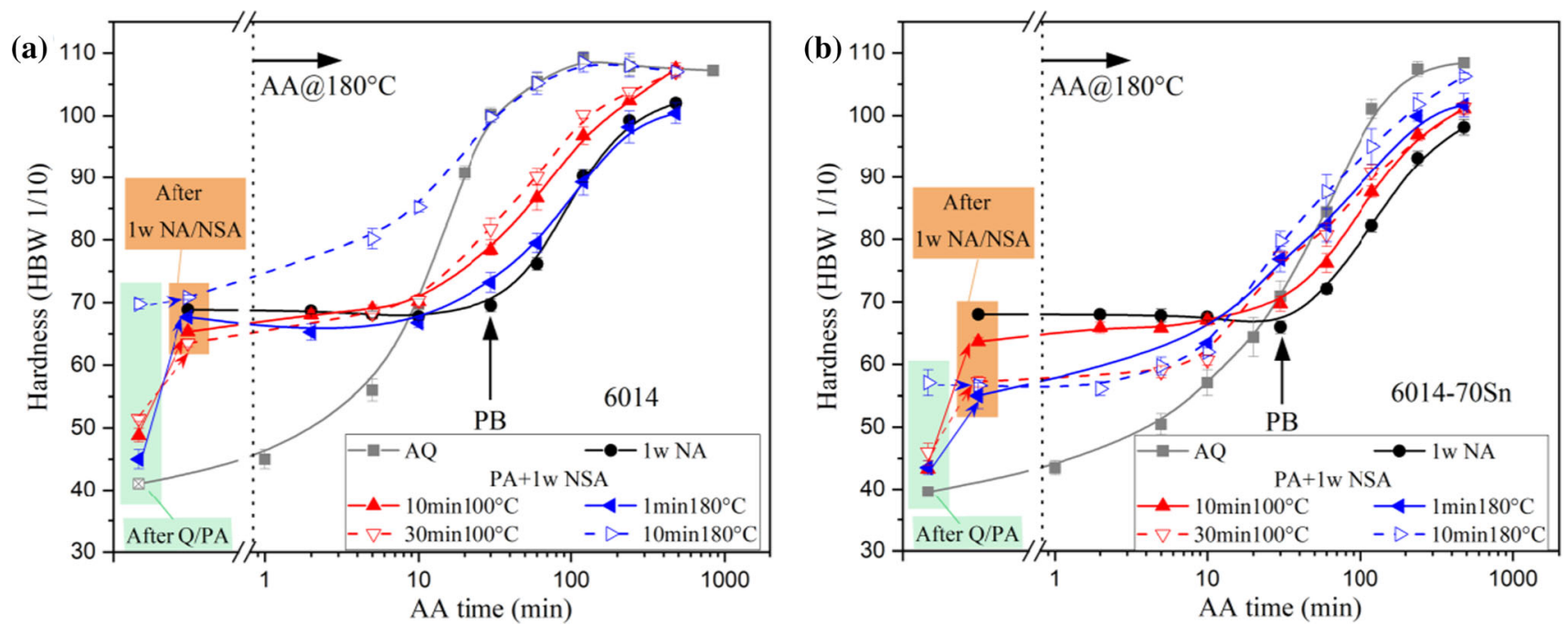

Figure 5 Hardness evolution in 1 week of NA/NSA and during subsequent AA in alloys a 6014 and b 6014-70Sn.

To unveil the structural origin of hardness evolution, microstructures of 6014(Sn) alloys after different heat treatments were further investigated by brightfield TEM. After $4 \mathrm{~h}$ of direct AA, densely distributed precipitates are found in both alloys (Fig. 6a, b), while only few precipitates are observed in the alloys with 1 week of prior NA included (Fig. 6c, d). Additional $30 \mathrm{~min} \mathrm{PA}$ at $100{ }^{\circ} \mathrm{C}$ before NA is found to increase the number density of precipitates, and this behaviour is more pronounced for alloy 6014 (Fig. 6e, f). For both alloys, $10 \mathrm{~min}$ PA at $180{ }^{\circ} \mathrm{C}$ also promotes the formation of precipitates with even higher number density than for $30 \mathrm{~min} \mathrm{PA}$ at $100{ }^{\circ} \mathrm{C}$, as illustrated in Fig. 6g, h. The average precipitate crosssection is estimated by measuring at least 200 precipitates and the results are listed in Table 2. It can be found that precipitates in the two alloys after $4 \mathrm{~h}$ AA have similar cross-sections, while 1 week of NA

(a) 4h AA

(c) lw NA + 4h AA

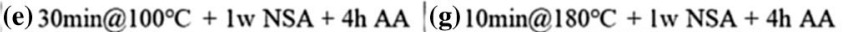
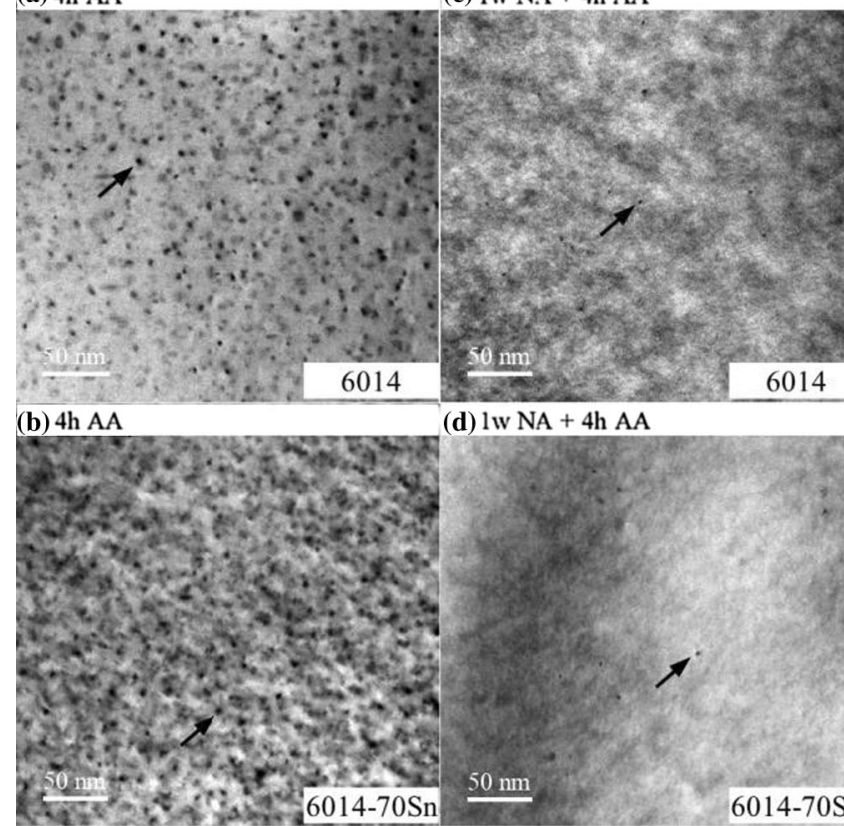

(d) l $\mathrm{w} \mathrm{NA}+4 \mathrm{~h} \mathrm{AA}$

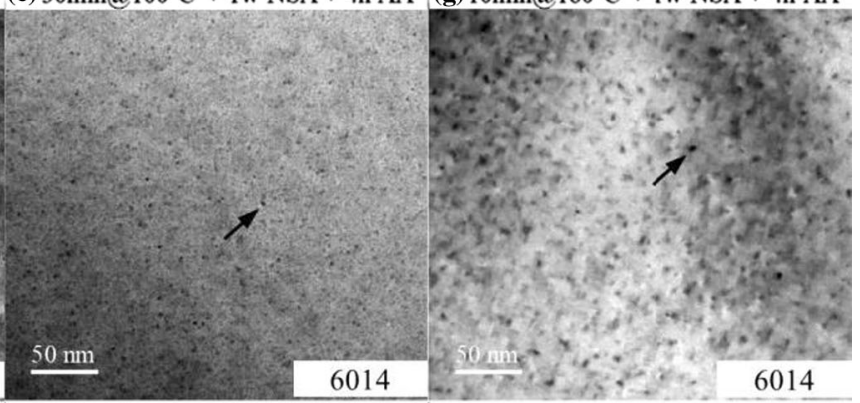

(f) $30 \mathrm{~min} @ 100^{\circ} \mathrm{C}+1 \mathrm{w} \mathrm{NSA}+4 \mathrm{~h} \mathrm{AA}$ (h) $10 \mathrm{~min} @ 180^{\circ} \mathrm{C}+\mathrm{lw} \mathrm{NSA}+4 \mathrm{~h} \mathrm{AA}$

Figure 6 Bright-field TEM images of alloys 6014 and 6014-70Sn after $4 \mathrm{~h} \mathrm{AA} \mathrm{a,} \mathrm{b}$; after 1 week NA and $4 \mathrm{~h} \mathrm{AA} \mathbf{c}$, d; after 30 min $\mathrm{PA}$ at $100{ }^{\circ} \mathrm{C}, 1$ week NSA and $4 \mathrm{~h} \mathrm{AA} \mathrm{e,} \mathrm{f} \mathrm{and} \mathrm{after} 10$ min PA at

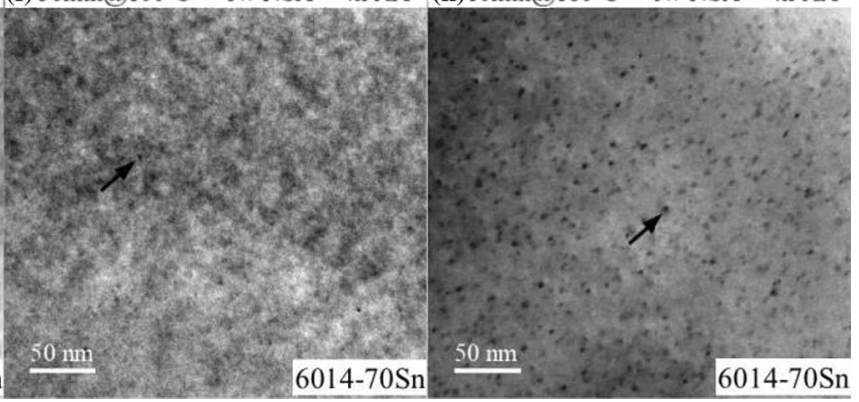

$180{ }^{\circ} \mathrm{C}, 1$ week NSA and $4 \mathrm{~h}$ AA $\mathbf{g}, \mathbf{h}$, respectively. Black arrows point at cross-sections of the precipitates formed. All images were taken in the $[100]_{\mathrm{Al}}$ zone axis. 
Table 2 Average cross-sections of precipitates formed in alloys 6014(Sn) for selected ageing conditions

\begin{tabular}{|c|c|c|c|c|}
\hline $\begin{array}{l}\text { Alloy \& } \\
\text { condition }\end{array}$ & $4 \mathrm{~h} \mathrm{AA}$ & $1 \mathrm{w} \mathrm{NA}+4 \mathrm{~h} \mathrm{AA}$ & $\begin{array}{l}30 \min @ 100{ }^{\circ} \mathrm{C}+1 \mathrm{w} \mathrm{NSA}+4 \mathrm{~h} \\
\mathrm{AA}\end{array}$ & $\begin{array}{l}10 \min @ 180{ }^{\circ} \mathrm{C}+1 \mathrm{w} \mathrm{NSA}+4 \mathrm{~h} \\
\mathrm{AA}\end{array}$ \\
\hline 6014 & $(7.46 \pm 5.18) \mathrm{nm}^{2}$ & $(1.72 \pm 1.08) \mathrm{nm}^{2}$ & $(2.36+1.04) \mathrm{nm}^{2}$ & $(6.96+4.14) \mathrm{nm}^{2}$ \\
\hline 6014-70Sn & $(7.61 \pm 5.18) \mathrm{nm}^{2}$ & $(1.35 \pm 0.85) \mathrm{nm}^{2}$ & $(3.93+2.74) \mathrm{nm}^{2}$ & $(10.07+5.13) \mathrm{nm}^{2}$ \\
\hline
\end{tabular}

notably decreases their size. PA at both $100{ }^{\circ} \mathrm{C}$ and $180{ }^{\circ} \mathrm{C}$ shows potential in promoting the growth of precipitates, especially for alloy 6014-70Sn pre-aged at $180{ }^{\circ} \mathrm{C}$.

To determine the type of precipitates observed in bright-field TEM, they were characterized by atomicresolution HAADF-STEM as presented in Fig. 7. "Eye-like" structures (marked by dashed orange circles) are frequently observed for precipitates formed in both alloys after all the treatments. It is also noticed that bright dots can be clearly identified inside the precipitates formed in alloy 6014-70Sn (labelled by red arrows). For the HAADF-STEM technique, the image intensity is proportional to $Z^{1.7-1.9}$ [27-29] with $\mathrm{Z}$ as the atomic number, and the bright dots observed will be further discussed in detail and attributed to Sn substitution in "Precipitation during artificial ageing (AA) in the presence of $\mathrm{Sn}^{\prime \prime}$ section. Another interesting finding for the Sn-added alloy is that the precipitate areas surrounding the bright dots show unclear lattice structure and appear to be disordered. Moreover, some PA clusters possess the similar FCC structure as Al matrix (spots in fast Fourier transform patterns are only from $\mathrm{Al}$ ) can also be found in the alloys after $4 \mathrm{~h}$ direct AA (Supplementary Fig. S1). The bright dots indicate the existence of $\mathrm{Sn}$ in the PA clusters formed in alloy 6014-70Sn (Supplementary Fig. S1c).

\section{Effects of natural ageing on pre-ageing (PA) of alloy 6014-70Sn}

The effect of an additional initial NA step on the various ageing behaviours of alloy 6014-70Sn is shown in Fig. 8. Compared to the as-quenched alloy, the DSC trace obtained for a sample after $8 \mathrm{~h}$ NA

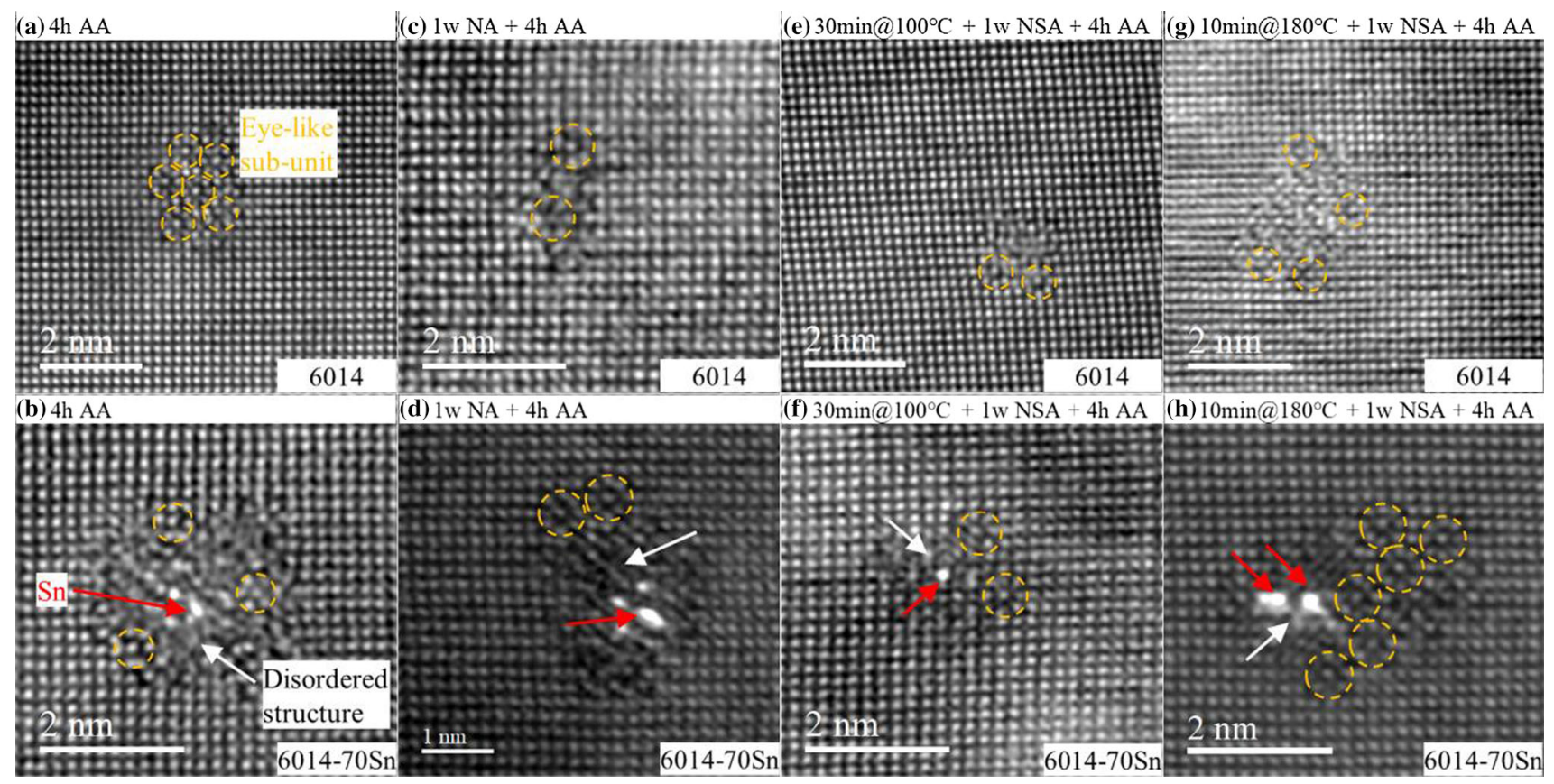

Figure 7 HAADF-STEM micrographs of precipitates in alloys 6014(Sn) after heat treatments corresponding to Fig. 6. Dashed orange circles mark the typical "eye-like" units, while red and white arrows point to the bright dots and disordered structure inside the precipitates, respectively. 

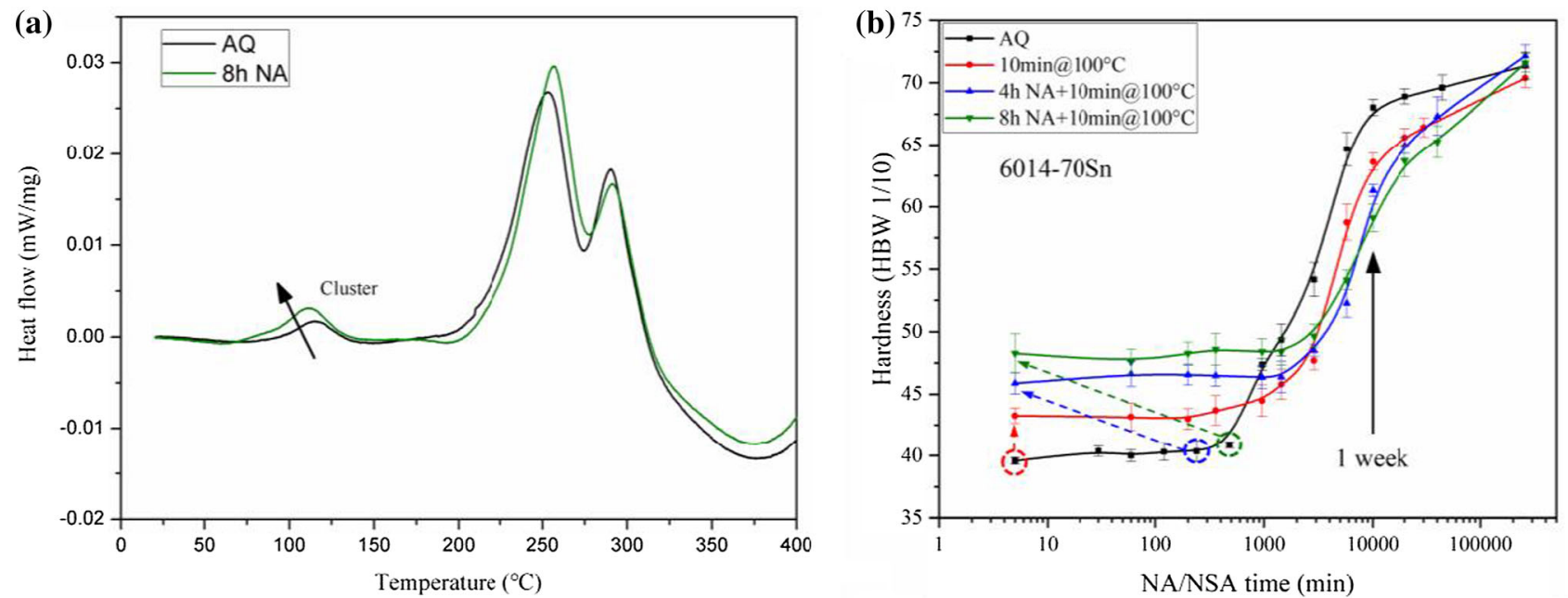

(c)

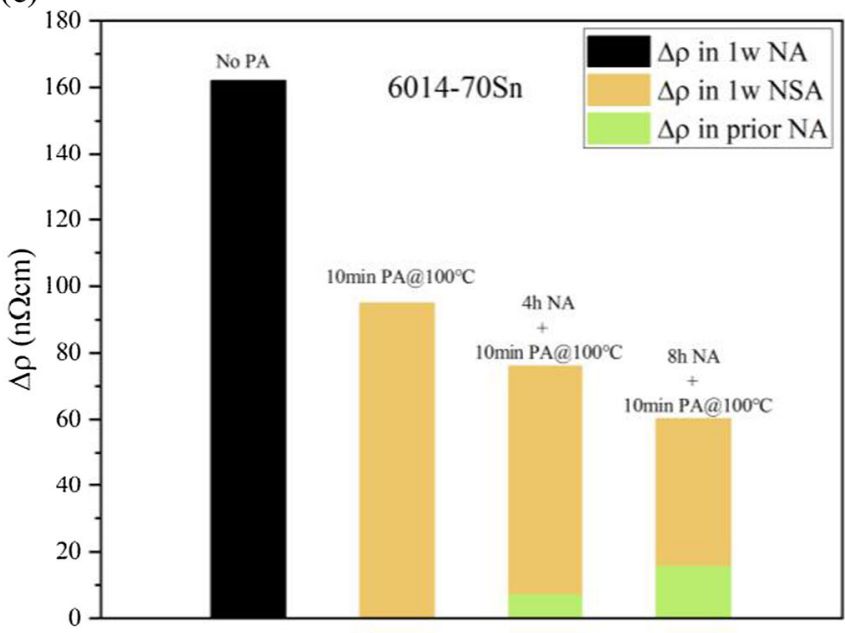

(d)

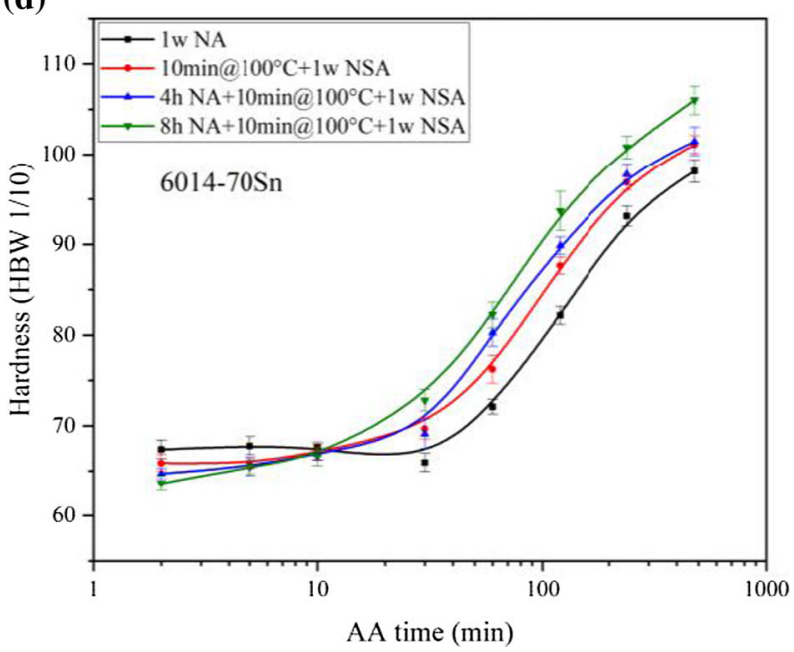

Figure 8 a DSC traces for alloy 6014-70Sn directly after solutionising and quenching (AQ, black, same data as in Fig. $4 \mathrm{~b}$ but different scale) and after $8 \mathrm{~h}$ of NA (green). $\mathbf{b}-\mathbf{d}$ Influence of PA $\left(10 \mathrm{~min}\right.$ at $\left.100{ }^{\circ} \mathrm{C}\right)$ and additional NA ( $4 \mathrm{~h}$ and $\left.8 \mathrm{~h}\right)$ before PA on $\mathbf{b}$ the hardness evolution during NA/NSA, $\mathbf{c} \Delta \rho$ in 1 week of

NA/NSA and (d) AA after 1 week of NA/NSA. The hardness data for the black and red curves in $\mathbf{b}$ and $\mathbf{d}$ are taken from Fig. 2a and Fig. 5b, respectively. The resistivity data for the cases of "No PA" and "10 min PA without NA" in c are taken from Fig. 3.

exhibits a larger peak " 1 " with a lower peak temperature (Fig. 8a). NA up to $8 \mathrm{~h}$ hardly changes hardness (black curve in Fig. 8b), but promotes the hardening response during the subsequent $10 \mathrm{~min}$ PA at $100{ }^{\circ} \mathrm{C}$, which becomes more pronounced with an increase of NA time (see dotted arrows in Fig. 8b). Moreover, the delaying effect of PA on the following NSA is further enhanced by NA and the hardness value reached after 1 week of NSA is also notably reduced. Electrical resistivity measurements were also carried out to evaluate the effect of NA (Fig. 8c):

The resistivity increase during 1 week of NA (1st bar) is strongly reduced by $10 \mathrm{~min} \mathrm{PA}$ at $100{ }^{\circ} \mathrm{C}$ (2nd bar) and can be further suppressed by NA prior to PA (last 2 bars). Even when we consider the total resistivity increase at RT including NA (green) and NSA (orange), much lower values are still found when NA is performed. In addition, during final AA at $180{ }^{\circ} \mathrm{C}$ after 1 week of NSA, NA before PA also gives rise to faster ageing kinetics and superior hardening response (Fig. 8d). 


\section{Discussion}

\section{Effect of Sn on clustering during natural (secondary) (NA/NSA) and pre-ageing (PA)}

During NA of solutionised and quenched alloys, the diffusion of solute atoms leads to the formation of NA clusters with the assistance of quenched-in vacancies. These NA clusters can act as obstacles for moving dislocations and contribute to the hardening of alloys, see Fig. 2. On the other hand, NA clusters also give rise to additional electron scattering [30], which results in an increase in electrical resistivity (Fig. 3). For alloy 6014-70Sn, the found retarded hardness and resistivity increase during NA can be explained by the strong interaction between $\mathrm{Sn}$ atoms and vacancies with an energy around 0.25 to $0.28 \mathrm{eV}$ [31, 32]. Our previous work has also revealed that even at a temperature as high as $250{ }^{\circ} \mathrm{C}$ vacancies can be bound by Sn for a notable period [26]. As a result, vacancy-assisted solute diffusion is retarded and NA kinetics is slowed down.

PA has been proposed to reduce and even suppress subsequent clustering at RT [11, 33], in agreement with the observed slower kinetics of hardness and resistivity evolution during NSA. Two mechanisms should account for this: first, the decreased solute supersaturation after formation of PA clusters; second, the lowered vacancy concentration after PA (vacancies either go to sinks or are trapped by preformed clusters) [26]. For the effect of Sn addition, much slower NSA kinetics is still found in alloy 6014-70Sn than in alloy 6014 after the same PA treatments (Fig. 2 and Fig. 3). Therefore, it appears that although the Sn-vacancy binding might weaken at PA temperatures, $\mathrm{Sn}$ atoms interact with vacancies strongly again after quenching and slow down the kinetics of NSA. Despite the slower ageing kinetics during NSA in alloy 6014-70Sn than in alloy 6014, the total increment of resistivity (Fig. 3) after the same PA treatment at $100{ }^{\circ} \mathrm{C}$ is eventually larger in alloy 6014-70Sn, i.e. the curves cross. As the formation of PA clusters at $100{ }^{\circ} \mathrm{C}$ is still retarded by $\mathrm{Sn}$ addition (inset in Fig. 2a), a lower consumption of solutes during PA in alloy 6014-70Sn can be deduced. Moreover, because Sn alters the ageing course only through controlling vacancy migration [34], the larger NSA potential in alloy 6014-70Sn can be attributed to more available residual solutes.
We now analyse the alloy after 1 week of NA/ NSA. The reduction of the cluster peak in the DSC traces (Fig. 4a, b) is associated with the reduction of solute atoms and vacancies, which are consumed during formation of NA clusters. Such NA clusters are not stable, as confirmed by the observed dissolution trough. In addition, it can be seen that although $\mathrm{Sn}$ addition slows down the formation of NA clusters, both 6014 and 6014-70Sn alloys show a similar hardness increment, resistivity change and area of dissolution trough during 1 week of NA (Fig. 9a), revealing the formation of a comparable amount of NA clusters in the presence of Sn. For PA samples, NA clustering (Fig. 9a) is reduced, in line with the discussion in last paragraph. In addition, both PA temperature and $\mathrm{Sn}$ addition are found to have an influence on the effect of PA. Specifically, PA at $100{ }^{\circ} \mathrm{C}$ is more effective in alloy 6014 than in alloy 6014-70Sn, while alloy 6014-70Sn is more significantly influenced by PA at $180{ }^{\circ} \mathrm{C}$ (as indicated by the orange dashed arrows Fig. 9a). The different vacancy behaviours depending on the PA temperatures in the presence of $\mathrm{Sn}$ should be the reason for this. Because a short exposure to $180{ }^{\circ} \mathrm{C}$ can release vacancies from $\mathrm{Sn}$, one can expect a faster formation of PA clusters and a faster vacancy loss compared to exposure to $100{ }^{\circ} \mathrm{C}$. At the same time, the difference between the PA clustering rate of alloys with and without $\mathrm{Sn}$ is also reduced at $180{ }^{\circ} \mathrm{C}$. During ensuing NSA, Sn atoms become effective again in trapping vacancies. All these factors result in the superior capability of the combination of $\mathrm{Sn}$ addition and PA at $180{ }^{\circ} \mathrm{C}$ to inhibit NSA for 1 week.

\section{Precipitation during artificial ageing (AA) in the presence of Sn}

In the condition "AA right after quenching", the generally accepted assumption is that high solute supersaturation and, for a very short period, possibly also the high vacancy concentration can promote the formation of precipitates [8, 35]. This is in good agreement with the observed finely dispersed precipitates after $4 \mathrm{~h}$ AA (Fig. 6a, b). Atomic-resolution HAADF images (Fig. 7a, b) reveal that precipitates formed in both alloys contain "eye-like" structures, which have been claimed to be the sub-units of the main hardening phase- $\beta^{\prime \prime}$ [36]. Thus, the fastest hardness increases can be explained (Fig. 5a, b). In addition, different from the pure $\beta^{\prime \prime}$ found in alloy 


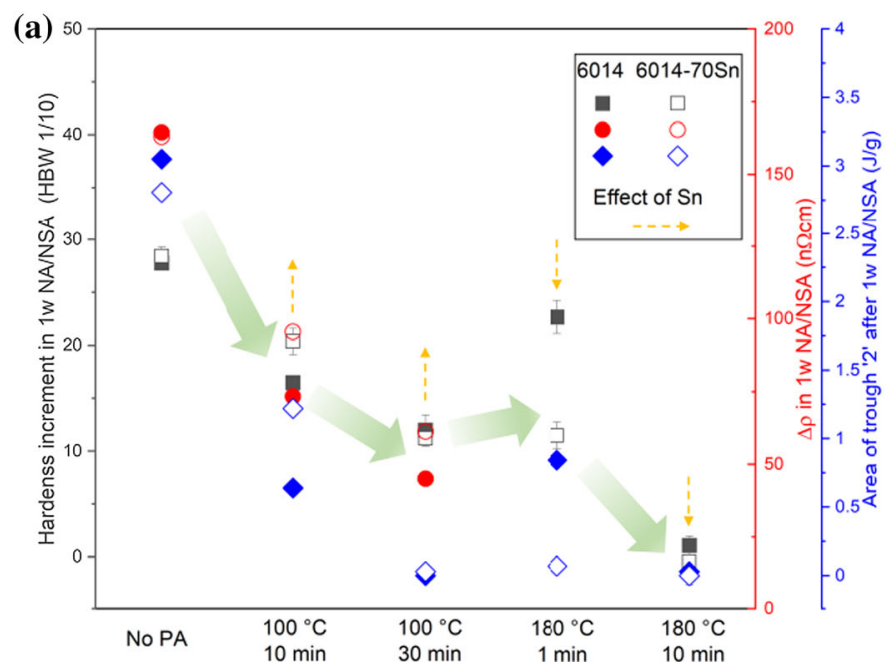

Figure 9 a Hardness increment, electrical resistivity change and area of DSC dissolution trough "2" after 1 week of NA/NSA. Orange dashed arrows represent the influence of Sn addition. $\mathbf{b}$ PB response after 1 week of NA/NSA obtained by subtracting the

6014, bright dots and a surrounding disordered structure are found after adding Sn (Fig. $7 b$ ). As heavier atoms can give rise to brighter contrast in the HAADF-STEM mode [27-29] the observed brighter dots inside precipitates can be attributed to the incorporation of $\mathrm{Sn}, \mathrm{Fe}$ and/or Mn atoms. However, if Fe or Mn were included in precipitates, they should also be observable in alloy 6014. Since bright dots are found only in the Sn-added alloy, they must be Sn atoms. The existence of $\mathrm{Sn}$ atoms in precipitates formed by artificially ageing $\mathrm{Al}-\mathrm{Mg}-\mathrm{Si}-\mathrm{Sn}$ alloys has also been evidenced in previous studies, not only experimentally by atom probe tomography $[9,37]$ and EDS measurements at near-atomic resolution [38] but also by density functional theory calculations [38]. This finding provides evidence that Sn atoms can capture vacancies, diffuse and participate in AA precipitation. Regarding the disordered structure inside precipitates, Liu et al. [38], who studied the precipitation behaviours of an $\mathrm{Al}-\mathrm{Mg}-\mathrm{Si}-\mathrm{Sn}$ alloy aged at $250{ }^{\circ} \mathrm{C}$, attributed it to the formation of $\beta^{\prime} / \beta^{\prime \prime}$ composites. In our study, however, the ageing temperature $\left(180^{\circ} \mathrm{C}\right)$ and time $(4 \mathrm{~h})$ applied are apparently not enough to trigger the formation of $\beta^{\prime}$. Moreover, Mørtsell et al. [39] reported that Ge can induce a disordered structure in $\mathrm{Al}-\mathrm{Mg}-\mathrm{Si}$ alloy aged at $180{ }^{\circ} \mathrm{C}$ by replacing $\mathrm{Si}$ in precipitates. Therefore, considering the chemical similarity between $\mathrm{Sn}, \mathrm{Ge}$ and $\mathrm{Si}$, the disorder found is assumed to be caused by the replacement of $\mathrm{Si}$ with $\mathrm{Sn}$ atoms in $\beta^{\prime \prime}$. This

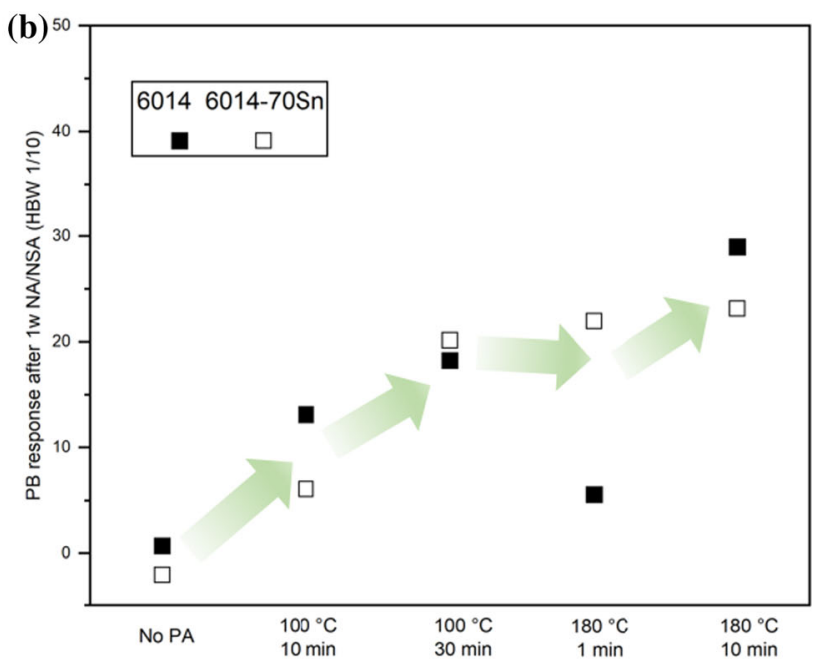

hardness after NA/NSA from PB hardness. Green arrows in a and b show the inverse correlation between NSA response and PB response. Data are extracted from Figs. 2, 3, 4 and 5.

assumption also applies to the precipitate structure formed in artificially aged alloys with prior NA and PA (Fig. $7 \mathrm{~d}, \mathrm{f}, \mathrm{h}$ ). Due to the attractive interaction between $\mathrm{Mg}$ and $\mathrm{Sn}$ [40], one may also expect the formation of $\mathrm{Mg}_{2} \mathrm{Sn}$. However, no such phase has been identified in the current work, in agreement with a series of previous reports [9, 38, 41]. According to Weng et al. [42], who studied Al-Mg-Si alloys containing Sn ranging from 0 to $0.2 \mathrm{wt}$. \%, the failure to observe $\mathrm{Mg}_{2} \mathrm{Sn}$ phase might be a result of the extremely low concentration of $\mathrm{Sn}$.

After 1 week of NA, the number density (Fig. 6e-h) and average cross-section (Table 2) of $\beta^{\prime \prime}$ formed during AA are all reduced, resulting in the reduced hardening response and postponed $\beta^{\prime \prime}$ DSC peak. Such negative effect is associated with the imprisoned vacancies and reduced solute supersaturation during NA. The potential of $\mathrm{Sn}$ in promoting AA of naturally aged $\mathrm{Al}-\mathrm{Mg}-\mathrm{Si}$ alloys is not observed (Fig. $5 \mathrm{~b}$ and Fig. 6d). This means that although NA clustering is slowed down by $\mathrm{Sn}$ generally, its negative effect on the following AA can still set in if sufficient clusters have formed given that the NA time has been long enough. It has also been found that PA in both alloys can significantly increase the precipitate number density (Fig. 6e-h) and average crosssection (Table 2), contributing to the improvement of hardness (Fig. 5a, b) and thus, mitigating the negative effect of NA on AA. One possible reason is the suppression of NSA clustering caused by the reduced 
solute and vacancy concentrations after PA. This is supported by the correlation between the $\mathrm{PB}$ response and the extent of NSA suppression (see thick green arrows in Fig. 9a, b). Another possible reason for the enhanced AA behaviour could be that PA clusters are transformable precursors for $\beta^{\prime \prime}$. For PA clusters, the average $\mathrm{Mg} / \mathrm{Si}$ ratio $(\sim 1.0[15,43])$ is higher than for NA clusters ( 0.66 [15]) and closer to that of $\beta^{\prime \prime}(0.9-1.1[15,20])$. Moreover, their size is larger than the critical size for nucleation at AA temperature [20,44]. Both factors enable PA clusters to act as nuclei for $\beta^{\prime \prime}$ during ensuing AA. The broader DSC peak for $\beta^{\prime \prime}$, the much higher number density and larger average cross-section of $\beta^{\prime \prime}$ observed after PA are thought to be the result of the existence of nuclei for $\beta^{\prime \prime}$.

In engineering practice, formability before panel stamping must be considered, which requires a low alloy strength after PA and NSA. It has been shown that alloy 6014 possesses relatively higher hardness after 1 week of NSA than the Sn-added one (orange boxes in Fig. 5a, b), either resulting from the higher PA hardness or from the NSA response. Evidently, in alloy 6014-70Sn the strongly delayed PA and NSA processes help to meet the formability requirement, while the good AA response can be ensured by a higher PA temperature.

A schematic showing the influence of Sn on the ageing behaviour of $\mathrm{Al}-\mathrm{Mg}-\mathrm{Si}$ alloys is given in Fig. 10. In the as-quenched Sn-free alloy, vacancies are free or attached to solutes weakly and transport of solutes during the subsequent PA and the associated formation of PA clusters is facilitated. NA clustering happens during the following NSA with the residual vacancies and solutes. In the final AA step, some NA clusters dissolve and some remain stable, while PA clusters further grow into $\beta^{\prime \prime}$. In comparison, vacancies are likely to be trapped strongly by added Sn atoms after quenching. When PA treatment is applied, Sn-vacancy binding is weakened but still exists, and the amount of PA clusters formed is reduced. In the following NSA, the diffusion of vacancies is again strongly slowed down in the presence of $\mathrm{Sn}$ and therefore NA clustering is suppressed. In the final AA treatment, $\mathrm{Sn}$ atoms can participate in the formation of $\beta^{\prime \prime}$-type precipitates and cause disordered phase by occupying the original Si position.

\section{Sn-induced positive effect of natural ageing (NA)}

Surprisingly, the application of NA before PA can improve the performance of PA at $100{ }^{\circ} \mathrm{C}$ in alloy 6014-70Sn (Fig. 8). This is contrary to the findings in $\mathrm{Sn}$-free Al-Mg-Si alloy reported by Torsæter et al. [43], where the formation of PA clusters is adversely influenced by 1 week of NA, due to the depletion of solute in the vicinity of the NA clusters formed. However, it has also been speculated that Si-vacancy

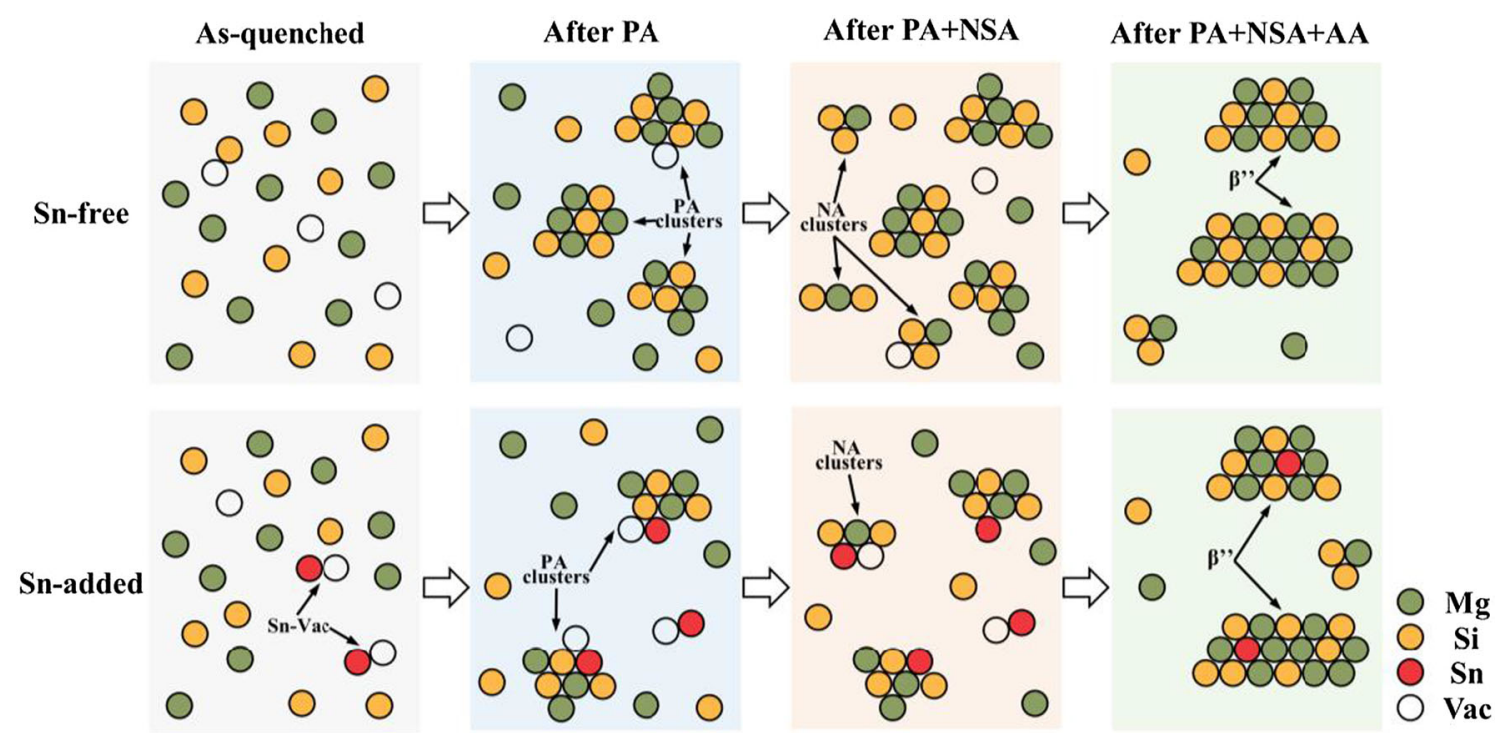

Figure 10 Schematic diagram showing the influence of Sn on the ageing behaviour starting from the as-quenched state to after PA, after $\mathrm{PA}+\mathrm{NSA}$ and after PA + NSA + AA. 
complexes or small Si clusters formed during quenching are able to promote the formation of PA clusters [11]. Therefore, we suspect that the discrepancy between the different roles of NA clusters during PA might be associated to their size, pointing at the NA clustering process being modified by $\mathrm{Sn}$ addition. Compared to the Sn-free alloy, the distance that solutes in the presence of Sn can diffuse in unit time during NA is largely reduced owing to the decreased number of available vacancies (as described in "Effect of $\mathrm{Sn}$ on clustering during natural (secondary) (NA/NSA) and pre-ageing (PA)" section). Consequently, smaller but more densely distributed clusters are formed in alloy 6014-70Sn than in alloy 6014. This is supported by our previous resistivity measurements [34], as well as by a comparable phenomenon observed in $\mathrm{Al}-\mathrm{Mg}-\mathrm{Si}$ alloys containing $\mathrm{Cu}$ atoms, which also have stronger binding with vacancies than $\mathrm{Mg} / \mathrm{Si}$ solutes [45]. After $8 \mathrm{~h}$ of NA, clusters are formed. Although they are not large enough to induce hardening more than marginally (black curve in Fig. 8b), they can result in an increased electrical resistivity (Fig. 8c). On the one hand, these small clusters will further grow into larger NA clusters at RT, as revealed by the appearance of hardening after an incubation period of $8 \mathrm{~h}$ in Fig. $8 \mathrm{~b}$. On the other hand, the elevated PA hardness after NA (Fig. 8b) might indicate that these clusters can transform into PA clusters at $100{ }^{\circ} \mathrm{C}$. Moreover, the broadened DSC clustering peak (Fig. 8a), which is related to the formation of PA clusters considering a peak temperature much higher than RT, also points at promoted PA kinetics. As a result, the accelerated formation of PA clusters suppresses NSA (Fig. 8b, c) and promotes AA kinetics and response (Fig. 8d).

\section{Conclusions}

We investigated the combined effects of $\mathrm{Sn}$ addition and pre-ageing (PA) on the ageing behaviour of Al$\mathrm{Mg}-\mathrm{Si}$ alloys, aiming to find a favourable combination that suppresses natural secondary ageing (NSA) and enhances subsequent artificial ageing (AA).

1. PA can suppress the formation of natural ageing (NA) clusters and improve the AA kinetics and response after 1 week of NSA in alloys with and without Sn.
2. The strong interaction between $\mathrm{Sn}$ and vacancies notably delays PA kinetics at $100{ }^{\circ} \mathrm{C}$. Therefore, a higher PA temperature (e.g. $180^{\circ} \mathrm{C}$ ) is required for a more effectively suppressed NSA and a larger AA response in Sn-added alloy by weakening the Sn-vacancy binding.

3. An undesired high hardness for Sn-free alloy after PA and subsequent NSA can be lowered by the addition of Sn while maintaining the AA potential.

4. The effect of PA at $100{ }^{\circ} \mathrm{C}$ in $6014-70 S n$ can be promoted by prior NA, which can be ascribed to the transformation of Sn-induced small clusters formed at RT to PA clusters when aged at $100{ }^{\circ} \mathrm{C}$.

\section{Acknowledgements}

The Deutsche Forschungsgemeinschaft (DFG) partially funded this project (Ba1170/22). Xingpu Zhang thanks the China Scholarship Council (CSC) for a research fellowship (No. 201506170013). We thank Dr. Zeqin Liang and David Leyvraz of Novelis Research and Technology Center Sierre for providing the alloys.

\section{Funding}

Open Access funding enabled and organized by Projekt DEAL.

\section{Declarations}

Conflict of interest The authors declare no conflict of interest.

Supplementary Information: The online version contains supplementary material available at http s://doi.org/10.1007/s10853-021-06654-y.

Open Access This article is licensed under a Creative Commons Attribution 4.0 International License, which permits use, sharing, adaptation, distribution and reproduction in any medium or format, as long as you give appropriate credit to the original author(s) and the source, provide a link to the Creative Commons licence, and indicate if changes were made. The images or other third party material in this article are included in the article's Creative Commons 
licence, unless indicated otherwise in a credit line to the material. If material is not included in the article's Creative Commons licence and your intended use is not permitted by statutory regulation or exceeds the permitted use, you will need to obtain permission directly from the copyright holder. To view a copy of this licence, visit http://creativecommons.org/licen ses/by $/ 4.0 /$.

Supplementary Information: The online version contains supplementary material available at http s:/ /doi.org/10.1007/s10853-021-06654-y.

\section{References}

[1] Zandbergen HW, Andersen SJ, Jansen J (1997) Structure determination of Mg5Si6: particles in Al by dynamic electron diffraction studies. Science 277:1221-1225. https://doi. org/10.1126/science.277.5330.1221

[2] Miao WF, Laughlin DE (1999) Precipitation hardening in aluminum alloy 6022. Scr Mater 40:873-878. https://doi.org/ 10.1016/S1359-6462(99)00046-9

[3] Pashley DW, Rhodes JW, Sendorek A (1966) Delayed ageing in aluminium-magnesium-silicon alloys: effect on structure and mechnical properties. J Inst Met London 94:41-49

[4] Brenner P, Kostron H (1939) Über die Vergütung der Aluminium-Magnesium-Silizium- Legierungen (Pantal). Zeitsschrift für Met 31(4):89-97

[5] Martinsen FA, Ehlers FJH, Torsæter M, Holmestad R (2012) Reversal of the negative natural aging effect in $\mathrm{Al}-\mathrm{Mg}-\mathrm{Si}$ alloys. Acta Mater 60:6091-6101. https://doi.org/10.1016/j. actamat.2012.07.047

[6] Aruga Y, Kozuka M, Takaki Y, Sato T (2015) Formation and reversion of clusters during natural aging and subsequent artificial aging in an $\mathrm{Al}-\mathrm{Mg}-\mathrm{Si}$ alloy. Mater Sci Eng A 631:86-96. https://doi.org/10.1016/j.msea.2015.02.035

[7] Falahati A, Lang P, Kozeschnik E (2012) Precipitation in Alalloy 6016 - the role of excess vacancies. Mater Sci Forum 706-709:317-322

[8] Pogatscher S, Antrekowitsch H, Leitner H et al (2011) Mechanisms controlling the artificial aging of Al-Mg-Si alloys. Acta Mater 59:3352-3363. https://doi.org/10.1016/j. actamat.2011.02.010

[9] Pogatscher S, Antrekowitsch H, Werinos M et al (2014) Diffusion on demand to control precipitation aging: application to Al-Mg-Si alloys. Phys Rev Lett 112:225701. h ttps://doi.org/10.1103/PhysRevLett.112.225701

[10] Werinos M, Antrekowitsch H, Ebner T et al (2016) Design strategy for controlled natural aging in $\mathrm{Al}-\mathrm{Mg}-\mathrm{Si}$ alloys.
Acta Mater 118:296-305. https://doi.org/10.1016/j.actamat. 2016.07.048

[11] Yamada K, Sato T, Kamio A (2000) Effects of quenching conditions on two-step aging behavior of $\mathrm{Al}-\mathrm{Mg}-\mathrm{Si}$ alloys. Mater Sci Forum 331-337:669-674

[12] Ding L, Weng Y, Wu S et al (2016) Influence of interrupted quenching and pre-aging on the bake hardening of $\mathrm{Al}-\mathrm{Mg}-$ Si Alloy. Mater Sci Eng A 651:991-998. https://doi.org/10. 1016/j.msea.2015.11.050

[13] Cao L, Rometsch PA, Couper MJ (2013) Effect of pre-ageing and natural ageing on the paint bake response of alloy AA6181A. Mater Sci Eng A 571:77-82. https://doi.org/10. 1016/j.msea.2013.01.065

[14] Yang Z, Liang Z, Leyvraz D, Banhart J (2019) Effect of preageing on natural secondary ageing and paint bake hardening in Al-Mg-Si alloys. Materialia 7:100413. https://doi.org/10. 1016/J.MTLA.2019.100413

[15] Zandbergen MW, Xu Q, Cerezo A, Smith GDW (2015) Study of precipitation in $\mathrm{Al}-\mathrm{Mg}-\mathrm{Si}$ alloys by atom probe tomography I. Microstructural changes as a function of ageing temperature. Acta Mater 101:136-148. https://doi.or g/10.1016/j.actamat.2015.08.017

[16] Engler O, Marioara CD, Aruga Y et al (2019) Effect of natural ageing or pre-ageing on the evolution of precipitate structure and strength during age hardening of $\mathrm{Al}-\mathrm{Mg}-\mathrm{Si}$ alloy AA 6016. Mater Sci Eng A 759:520-529. https://doi. org/10.1016/j.msea.2019.05.073

[17] Saga M, Sasaki Y, Kikuchi M et al (1996) Effect of preaging temperature on the behavior in the early stage of aging at high temperature for $\mathrm{Al}-\mathrm{Mg}-\mathrm{Si}$ alloy. Mater Sci Forum 217-222:821-826

[18] Serizawa A, Hirosawa S, Sato T (2008) Three-dimensional atom probe characterization of nanoclusters responsible for multistep aging behavior of an $\mathrm{Al}-\mathrm{Mg}-\mathrm{Si}$ alloy. Metall Mater Trans A 39:243-251. https://doi.org/10.1007/s11661007-9438-5

[19] Edwards GA, Stiller K, Dunlop GL, Couper MJ (1998) The precipitation sequence in $\mathrm{Al}-\mathrm{Mg}-\mathrm{Si}$ alloys. Acta Mater 46:3893-3904. https://doi.org/10.1016/S1359-6454(98)000 59-7

[20] Murayama M, Hono K (1999) Pre-precipitate clusters and precipitation processes in $\mathrm{Al}-\mathrm{Mg}-\mathrm{Si}$ alloys. Acta Mater 47:1537-1548. https://doi.org/10.1016/S1359-6454(99)000 33-6

[21] Marioara CD, Andersen SJ, Jansen J, Zandbergen HW (2003) The influence of temperature and storage time at RT on nucleation of the beta" phase in a $6082 \mathrm{Al}-\mathrm{Mg}-\mathrm{Si}$ alloy. Acta Mater 51:789-796. https://doi.org/10.1016/S1359-645 4(02)00470-6 
[22] Birol Y (2005) Pre-aging to improve bake hardening in a twin-roll cast Al-Mg-Si alloy. Mater Sci Eng A 391:175-180. https://doi.org/10.1016/j.msea.2004.08.069

[23] Zandbergen MW, Cerezo A, Smith GDW (2015) Study of precipitation in $\mathrm{Al}-\mathrm{Mg}-\mathrm{Si}$ alloys by atom probe tomography II. Influence of $\mathrm{Cu}$ additions Acta Mater 101:149-158. h ttps://doi.org/10.1016/j.actamat.2015.08.018

[24] Weng Y, Jia Z, Ding L et al (2018) Combined effect of preaging and $\mathrm{Ag} / \mathrm{Cu}$ addition on the natural aging and bake hardening in $\mathrm{Al}-\mathrm{Mg}-\mathrm{Si}$ alloys. Prog Nat Sci Mater Int 28:363-370. https://doi.org/10.1016/j.pnsc.2018.04.007

[25] Banhart J, Chang CST, Liang ZQ et al (2010) Natural aging in $\mathrm{Al}-\mathrm{Mg}-\mathrm{Si}$ alloys - a process of unexpected complexity. Adv Eng Mater 12:559-571. https://doi.org/10.1002/adem. 201000041

[26] Zhang X, Liu M, Sun H, Banhart J (2019) Influence of Sn on the age hardening behavior of $\mathrm{Al}-\mathrm{Mg}-\mathrm{Si}$ alloys at different temperatures. Materialia 8:100441. https://doi.org/10.1016/j. mtla.2019.100441

[27] Pennycook SJ, Jesson DE (1991) High-resolution Z-contrast imaging of crystals. Ultramicroscopy 37:14-38. https://doi. org/10.1016/0304-3991(91)90004-P

[28] Nellist PD, Pennycook SJ (1999) Incoherent imaging using dynamically scattered coherent electrons. Ultramicroscopy 78:111-124. https://doi.org/10.1016/S0304-3991(99)000170

[29] Yamazaki T, Kawasaki M, Watanabe K et al (2002) Effect of small crystal tilt on atomic-resolution high-angle annular dark field STEM imaging. Ultramicroscopy 92:181-189. h ttps://doi.org/10.1016/S0304-3991(02)00131-6

[30] Panseri C, Federighi T (1966) A resistometric study of preprecipitation in an aluminium-1.4 percent $\mathrm{Mg} 2 \mathrm{Si}$ alloy. J Inst Met London 94:99-197

[31] Wolverton C (2007) Solute-vacancy binding in aluminum. Acta Mater 55:5867-5872. https://doi.org/10.1016/j.actamat. 2007.06.039

[32] Lang P, Shan YV, Kozeschnik E (2014) The life-time of structural vacancies in the presence of solute trapping. Mater Sci Forum 794-796:963-970

[33] Yan Y (2014) Investigation of the negative and positive effects of natural aging on artificial aging response in Al$\mathrm{Mg}-\mathrm{Si}$ alloys. Technische Universität Berlin

[34] Liu M, Zhang X, Körner B et al (2019) Effect of Sn and In on the natural ageing kinetics of $\mathrm{Al}-\mathrm{Mg}-\mathrm{Si}$ alloys. Materialia 6:100261. https://doi.org/10.1016/j.mtla.2019.100261

[35] Madanat M, Liu M, Zhang X et al (2020) Co-evolution of vacancies and solute clusters during artificial ageing of $\mathrm{Al}-$ Mg-Si alloys. Phys Rev Mater 4:063608. https://doi.org/10. 1103/PhysRevMaterials.4.063608
[36] van Huis MA, Chen JH, Zandbergen HW, Sluiter MHF (2006) Phase stability and structural relations of nanometersized, matrix-embedded precipitate phases in $\mathrm{Al}-\mathrm{Mg}-\mathrm{Si}$ alloys in the late stages of evolution. Acta Mater 54:2945-2955. https://doi.org/10.1016/j.actamat.2006.02. 034

[37] Werinos M, Antrekowitsch H, Kozeschnik E et al (2016) Ultrafast artificial aging of $\mathrm{Al}-\mathrm{Mg}-\mathrm{Si}$ alloys. Scr Mater 112:148-151. https://doi.org/10.1016/j.scriptamat.2015.09. 037

[38] Liu C, Ma P, Zhan L et al (2018) Solute Sn-induced formation of composite $\beta^{\prime} / \beta^{\prime \prime}$ precipitates in $\mathrm{Al}-\mathrm{Mg}-\mathrm{Si}$ alloy. Scr Mater 155:68-72. https://doi.org/10.1016/j.scriptamat.2 018.06 .028

[39] Mørtsell EA, Marioara CD, Andersen SJ et al (2015) Effects of germanium, copper, and silver substitutions on hardness and microstructure in lean $\mathrm{Al}-\mathrm{Mg}-\mathrm{Si}$ alloys. Metall Mater Trans A Phys Metall Mater Sci 46:4369-4379. https://doi. org/10.1007/s11661-015-3039-5

[40] Hirosawa S, Nakamura F, Sato T (2007) First-principles calculation of interaction energies between solutes and/or vacancies for predicting atomistic behaviors of microalloying elements in aluminum alloys. Mater Sci Forum 561-565:283-286

[41] Tu W, Tang J, Zhang Y et al (2019) Influence of Sn on the precipitation and hardening response of natural aged Al$0.4 \mathrm{Mg}-1.0 \mathrm{Si}$ alloy artificial aged at different temperatures. Mater Sci Eng A 765:138250. https://doi.org/10.1016/j.mse a.2019.138250

[42] Weng Y, Xu Y, Ding L et al (2021) Effect of Sn contents on natural aging and precipitation hardening in $\mathrm{Al}-\mathrm{Mg}-\mathrm{Si}$ alloys. Mater Charact 179:111383. https://doi.org/10.1016/j. matchar.2021.111383

[43] Torsæter M, Hasting HS, Lefebvre W et al (2010) The influence of composition and natural aging on clustering during preaging in Al-Mg-Si alloys. J Appl Phys. https://d oi.org/10.1063/1.3481090

[44] Aruga Y, Kozuka M, Takaki Y, Sato T (2014) Evaluation of solute clusters associated with bake-hardening response in isothermal aged $\mathrm{Al}-\mathrm{Mg}-\mathrm{Si}$ alloys using a three-dimensional atom probe. Metall Mater Trans A Phys Metall Mater Sci 45:5906-5913. https://doi.org/10.1007/s11661-014-2548-y

[45] Liu M, Banhart J (2016) Effect of $\mathrm{Cu}$ and $\mathrm{Ge}$ on solute clustering in $\mathrm{Al}-\mathrm{Mg}-\mathrm{Si}$ alloys. Mater Sci Eng A 658:238-245. https://doi.org/10.1016/j.msea.2016.01.095

Publisher's Note Springer Nature remains neutral with regard to jurisdictional claims in published maps and institutional affiliations. 